\title{
Identificación bacteriana en teléfonos celulares de estudiantes de medicina que acuden o no, a un Hospital General en Mérida, Yucatán, México
}

\section{Bacterial identification on cell phones of medical students attending or not, at a General Hospital in Merida, Yucatan, Mexico}

\author{
CAAMAL-LEY, Angel D. $\dagger^{*}$, PUC-FRANCO, Miguel A., HEREDIA-NAVARRETE, Mario R., \\ LINDO-PEREZ, David y VARGAS-GONZALEZ, Alberto
}

Universidad Autónoma de Yucatán. Centro de Investigaciones Regionales “Dr. Hideyo Noguchi. Av. Itzáes, Centro, 97000 Mérida, Yuc.

ID 1 ${ }^{\text {er }}$ Autor: Angel D., Caamal-Ley / ORC ID: 0000-0002-9486-673, CVU CONACYT ID: 103523

ID 1er Coautor: Miguel A., Puc-Franco / ORC ID: 0000-0002-6016-8716, CVU CONACYT ID: 296453

ID $2^{\text {do }}$ Coautor: Mario R., Heredia-Navarrete / ORC ID: 0000-0001-9812-1772, CVU CONACYT ID: 1013438

ID $3^{\text {er }}$ Coautor: David, Lindo-Perez / ORC ID: 0000-0002-3376-0132, CVU CONACYT ID: 1007206

ID $4^{\text {to }}$ Coautor: Alberto, Vargas-Gonzalez / ORC ID: 0000-0001-8761-3990, CVU CONACYT ID: 60894

DOI: $10.35429 / \mathrm{JOHS} .2019 .19 .6 .21 .25$

Recibido Abril 10, 2019; Aceptado Junio 29, 2019

\begin{abstract}
Resumen
El teléfono móvil es una importante herramienta de comunicación, consulta e intercambio de información; estudios realizados en hospitales demostraron que los celulares del personal médico se encuentran contaminados por patógenos nosocomiales. Pero no se conoce bien las especies bacterianas que el teléfono celular alberga y que representan un riesgo potencial. Se analizaron los celulares de 30 alumnos de primer año de la carrera de médico cirujano que no acuden al hospital vs 30 alumnos que realizan sus prácticas en el hospital, para determinar las bacterias presentes. Se tomaron muestras con hisopos estériles humedecidos con solución salina isotónica. Los medios de cultivo empleados fueron agar McConkey y agar sal-manitol. Las pruebas bioquímicas realizadas fueron: citrato, MIO, lía, urea y TSI para la identificación de enterobacterias y pruebas de degradación manitol, coagulasa, catalasa y oxidasa para la identificación de estafilococos. Asimismo, se realizó frotis y tinción de Gram de las colonias aisladas. Encontrando principalmente Staphylococcus epidermidis, Staphylococcus aureus, Escherichia coli y Pseudomona sp. Se encontró diferencia en cuanto al número y especies bacterianas encontradas en los celulares de cada grupo de estudio. Representando un reservorio de bacterias potencialmente patógenas para el ser humano.
\end{abstract}

Teléfonos celulares, Hospitales, Bacterias

\begin{abstract}
The cell phone is an important tool for communication, consultation and information exchange; Studies carried out in hospitals have shown that cell phones of medical personnel are contaminated by nosocomial pathogens. However, the bacterial species that the cell phones house and their potential risk have not been determined. We analized the cell phones of 30 first-year medical students who do not visit the hospital in their studies vs. 30 students who perform their clerkship practices in hospitals, to determine the differences in bacterial loads. Samples were taken by sterile swabs moistened with isotonic saline. McConkey and salt-mannitol agar were used as culture media. The biochemical tests used for identification of enterobacteria were citrate, MIO, LIA, urea and TSI. Degradation tests of mannitol, coagulase, catalase and oxidase were used for the identification of staphylococci. Likewise, smears and Gram staining of the isolated colonies were performed. Staphylococcus epidermidis, Staphylococcus aureus, Escherichia coli and Pseudomona sp. were mainly found. Differences in number and bacterial species were found in the cell phones of each study group, representing a reservoir of potentially pathogenic bacteria for humans.
\end{abstract}

Cell phones, Hospitals, Bacteria

Citación: CAAMAL-LEY, Angel D., PUC-FRANCO Miguel A., HEREDIA-NAVARRETE Mario R., LINDO-PEREZ, David y VARGAS-GONZALEZ, Alberto. Identificación bacteriana en teléfonos celulares de estudiantes de medicina que acuden o no, a un Hospital General en Mérida, Yucatán, México. Revista de Ciencias de la Salud. 2019. 6-19: 21-25.

*Correspondencia al Autor (Correo Electrónico: angel.caamal@ correo.uady.mx)
$\dagger$ Investigador contribuyendo como primer Autor 


\section{Introducción}

Desde su aparición en la década de los setentas el teléfono celular ha obtenido un protagonismo cada vez más relevante en la sociedad, mismo que se ha incrementado con el advenimiento de los llamados teléfonos inteligentes, generando mayor uso, influencia y dependencia en los individuos. Sí bien los beneficios han sido grandes, a la par del incremento en su uso, surgen nuevas problemáticas.

Una de las principales es la contaminación bacteriana asociada al uso antihigiénico y cotidiano. Su empleo como medio de comunicación móvil implica contaminación potencial con bacterias de la microbiota del conducto auditivo, cavidad oral y piel, sumado a lo anterior existe también el riesgo con bacterias entéricas debido a su manejo antihigiénico, utilizando el dispositivo en espacios como baños.

La población desconoce de qué manera un dispositivo como el teléfono celular actúa como vehículo para transmisión de patógenos, y en consecuencia causantes de enfermedades infecciosas.

Adquiere una dimensión aun mayor, considerándola en el contexto de la práctica en área de la salud. En la práctica médica actual el teléfono móvil es una importante herramienta de comunicación, de consulta e intercambio de información.

Los resultados de varios estudios realizados en hospitales han demostrado que los celulares del personal médico se encuentran contaminados por patógenos nosocomiales.

De igual manera, la mayoría de los usuarios ignoran este hecho y no cumplen normas de cuidado o desinfección de los equipos, no practican el lavado de manos y utilizan el teléfono celular en áreas hospitalarias estériles. (Magdaleno, C, y cols., 2011; Muñoz Escobedo J., y cols, 2012; Ayalew, W., y cols., 2019; Shaebth, L. J., 2019).
Diversos estudios realizados en dispositivos electrónicos empleados por personal del área de la salud han arrojado aislamientos positivos, donde se destacan enterobacterias como Escherichia coli, Klebsiella spp. Citrobacter spp., Pseudomonas spp., Candida spp e inclusive SAMR, así como otras gram positivas y negativas resistentes a ampicilina y trimetoprima/sulfametoxazol. Aunque estos datos no son desconocidos por el personal de la salud, no se llevan a cabo hábitos y actitudes en la utilización de los teléfonos dentro de las áreas y mucho menos la práctica de desinfectar las superficies del celular de manera rutinaria. Lo anterior resulta importante, ya que son medidas necesarias para prevenir las infecciones nosocomiales de patógenos multi drogorresistentes por medio de los teléfonos celulares. (Hernández, Mauricio, y cols., 2011; Villacrés Yancha D \& Zurita Solís M., 2017; Bodena, D., y cols., 2019; Al Momani, W., y cols., 2019; Paz G, y cols 2014).

Los teléfonos celulares se convierten en vehículos de patógenos cuando entran en contacto con la cara, oídos, labios y manos de diferentes usuarios en distintas condiciones de salud. Además, la mayoría de las personas no comprende el riesgo inherente de compartir los teléfonos. Adquiere mayor relevancia cuando se trata de personas afines al área de la salud que, aunque conoce las medidas adecuadas de higiene, desinfección y el riesgo de contacto con microorganismos patógenos, no lleva a cabo las medidas necesarias para que estos aparatos no se conviertan en transmisores de ellos. Seguir encontrando porcentajes elevados de contaminación, se convierte en una problemática de interés general. Pero no se conoce bien las especies bacterianas que el teléfono celular alberga y que representan un riesgo potencial. De ahí el interés para realizar una investigación y conocer las especies bacterianas que alberga el teléfono de estudiantes que acuden a hospitales.

\section{Metodología}

Se trazó como objetivo identificar la variedad de microorganismos bacterianos presentes en los teléfonos celulares de un grupo de estudiantes de primer año de la licenciatura en Médico Cirujano de la Facultad de Medicina que no acuden al hospital vs. un grupo de estudiantes de la misma facultad y médicos internos de pregrado de un Hospital General. 


\section{Muestreo}

Se tomaron muestras por conveniencia, de 60 teléfonos celulares, 30 de alumnos de primer año sin contacto con ambiente hospitalario y 30 de médicos internos de pregrado del Hospital General. Para la toma de muestras, se emplearon hisopos estériles humedecidos con solución salina isotónica, rotándolo por la superficie anterior del teléfono celular, procurando abarcar toda su extensión.

Posteriormente el hisopo se colocó en un tubo microcentrífugo de $1.5 \mathrm{~mL}$ que contenía 1 $\mathrm{mL}$ de solución salina isotónica estéril y se almacenó a $4^{\circ} \mathrm{C}$, por no más de 12 horas, permitiendo la viabilidad de la muestra sin que exista un crecimiento significativo hasta la siembra en los medios de cultivos respectivos.

\section{Cultivos}

Con asa bacteriológica redonda previamente esterilizada, se realizó la siembra por el método de pentágono, en el agar: MacConkey (BD Bioxon, Becton Dickinson. México®), para la identificación de enterobacterias, y Sal-Manitol (BD Bioxon, Becton Dickinson. México®), para aislamiento selectivo de estafilococos, Se incubaron en estufa bacteriológica (Riossa serie: ECML. México®), a $37^{\circ} \mathrm{C}$ por 24 horas.

\section{Identificación de microorganismos}

A los cultivos positivos se les realizó un análisis descriptivo entre ambos medios para identificar las diferentes morfologías de las colonias. Posteriormente se realizaron las pruebas bioquímicas: citrato, MIO, LIA, urea y TSI para la identificación de enterobacterias y pruebas de degradación de manitol, coagulasa, catalasa y oxidasa para la identificación de estafilococos. Transcurridas 24 horas de incubación de las pruebas bioquímicas, se realizó el análisis bacteriológico con base a las tablas de reacciones bioquímicas de especies, subespecies, biogrupos de Murray P., y cols., 2009.

\section{Resultados}

Se observó crecimiento en la totalidad de los medios de cultivo. Las colonias desarrolladas en el medio Mc Conkey y sal-manitol fueron sometidas a pruebas bioquímicas específicas. Basados en las características cualitativas y cuantitativas de las colonias, se encontraron varios microorganismos patógenos, entre los que destaca Staphylococcus aureus y E scherichia coli, los cuales se encontraron en mayor porcentaje en los alumnos que acuden al hospital general, así como otras especies que potencialmente, podrían causar infecciones nosocomiales en pacientes inmunocomprometidos. Estos resultados se pueden ver en la Tabla 1.

\begin{tabular}{|l|r|r|r|}
\multicolumn{1}{|c|}{$\begin{array}{c}\text { Especie } \\
\text { Bacteriana }\end{array}$} & $\begin{array}{c}\text { Porcentaje } \\
\text { global }\end{array}$ & \multicolumn{3}{c|}{$\begin{array}{c}\text { Porcentaje por grupos } \\
\text { de primer } \\
\text { año }\end{array}$} & $\begin{array}{c}\text { Médicos } \\
\text { internos } \\
\text { de } \\
\text { pregrado }\end{array}$ \\
\hline $\begin{array}{l}\text { Staphylococcus } \\
\text { epidermidis }\end{array}$ & $41.66 \%$ & $70 \%$ & $13.33 \%$ \\
\hline $\begin{array}{l}\text { Staphylococcus } \\
\text { aureus }\end{array}$ & $26.66 \%$ & $10 \%$ & $43.33 \%$ \\
\hline Escherichia coli & $13.33 \%$ & $10 \%$ & $16.66 \%$ \\
\hline $\begin{array}{l}\text { Pseudomonas } \\
\text { sp }\end{array}$ & $6.66 \%$ & $3.33 \%$ & $10 \%$ \\
\hline Proteus sp & $5 \%$ & $3.33 \%$ & $6.66 \%$ \\
\hline Klebsiella sp & $3.33 \%$ & --- & $6.66 \%$ \\
\hline $\begin{array}{l}\text { Moraxella } \\
\text { catarrhalis }\end{array}$ & $1.66 \%$ & $3.33 \%$ & -- \\
\hline $\begin{array}{l}\text { Morganella } \\
\text { morganii }\end{array}$ & $1.66 \%$ & --- & $3.33 \%$ \\
\hline
\end{tabular}

Tabla 1 Especies bacterianas identificadas y su porcentaje global y por grupos

\section{Discusión}

Los resultados del presente trabajo evidencian el importante papel del teléfono celular como albergue y vehículo de trasmisión de microorganismos potencialmente patógenos.

Las especies identificadas en nuestro estudio fueron por orden de frecuencia Staphylococcus epidermidis (41.66\%), S. aureus (26.66\%), Escherichia coli (13.33\%), Pseudomonas sp. (6.66\%), Proteus sp (5\%), Klebsiella sp. (3.33\%) Moraxella catarrhalis (1.66\%), y Morganella morganii. (1.66\%).

Nuestros resultados no distan mucho de los reportados por otros estudios alrededor del mundo. 
Lemus-Espinoza et al. encontraron Staphylococcus aureus (29.5\%), Escherichia coli (19.3\%) y Pseudomonas aeruginosa (3.6\%). Aunque este estudio se realizó en población abierta, se destaca Pseudomona cuyo porcentaje fue mayor en nuestro estudio, posiblemente por tratarse de un ambiente hospitalario.

La presencia de enterobacterias implica una contaminación fecal de los teléfonos celulares y se explica por el incumplimiento de normas básicas de higiene como lo es el lavado de manos y la limpieza periódica del teléfono celular. Es destacable el hecho de que $S$. epidermdis haya sido el microorganismo identificado con mayor frecuencia en los teléfonos celulares en estudiantes de primer año mientras que entre los médicos internos de pregrado haya sido $S$. aureus. Esto podría deberse a que los últimos se hallan expuestos a una mayor diversidad bacteriana en el hospital.

Existe diferencia en cuanto al porcentaje de las especies bacterianas encontradas en cada grupo de estudio, posiblemente al diferente entorno en el que realizan sus actividades. Por lo que se puede concluir que el teléfono celular representa un reservorio y transportador de especies bacterianas potencialmente patógenas.

\section{Conclusiones}

Las especies encontradas en mayor porcentaje fueron Staphylococcus epidermidis, Staphylococcus aureus, Escherichia coli y Pseudomona sp. El mayor porcentaje de contaminación de especia bacterianas en las superficies de teléfonos celulares fue mayor en los estudiantes que acudían al Hospital General, posiblemente al estar en contacto con pacientes y personal médico. No existe en la población una cultura relacionada con la limpieza del teléfono celular, lo cual resulta una problemática de interés, debido a que los resultados de diversos estudios incluido este, son consistentes en los hallazgos de microorganismos y a pesar de conocerse el peligro potencial y diversos métodos de desinfección se sigue observando lo mismo por lo que se considera necesaria una regulación más estricta y estandarización en cuanto al empleo y la limpieza del teléfono celular en el medio hospitalario y en general con la población, por lo que la difusión de este y otros estudios resultaría de enorme relevancia para concientización no solo para trabajadores en el área de la salud y también para la población general.

\section{Referencias}

Al Momani, W., Khatatbeh, M., \& Altaany, Z. (2019). Antibiotic susceptibility of bacterial pathogens recovered from the hand and mobile phones of university students. Germs, 9(1), 9.

Ayalew, Workneh, Mulu, Wondemagegn \& Biadglegne, Fantahun. (2019). Bacterial contamination and antibiogram of isolates from health care workers' fomites at Felege Hiwot Referral Hospital, northwest Ethiopia. Ethiopian Journal of Health Development, 33(2).

Bodena, D., Teklemariam, Z., Balakrishnan, S., \& Tesfa, T. (2019). Bacterial contamination of mobile phones of health professionals in Eastern Ethiopia: antimicrobial susceptibility and associated factors. Tropical medicine and health, 47(1), 15.

Hernández, Mauricio, Barros, Camilo, Martínez, Nicolás, Olaya, Hernando, Villegas, Sonia \& Alvarez, Carlos. (2011). Frecuencia de colonización de staphylococcus aureus meticilino - resistente, de enterobacterias y de candida spp. en estetoscopios y teléfonos móviles en una unidad de cuidados intensivos neonatal. Revista Salud Bosque, 1(1), 17-24.

Lemus Espinoza, Druvic, Lemus, Rodney, Maniscalchi Badaoui, Maria Teresa, \& Bónoli, Stefano. (2015). Contaminación bacteriana y fúngica en equipos de telefonía móvil en Barcelona, estado Anzoátegui, Venezuela. Saber, 27(4), 547-553.

Magdaleno, C, Loría Castellanos, J \& Hernández Méndez, N. (2011). Frecuencia de contaminación de teléfonos celulares y estetoscopios del personal que labora en el Servicio de Urgencias.;6(3):142-147.

Muñoz Escobedo, José Jesús, Varela Castillo, Laura, Chávez Romero, Perla Berenice, Becerra Sánchez, Arian, \& Moreno García, María Alejandra. (2012). Bacterias patógenas aisladas de teléfonos celulares del personal y alumnos de la Clínica Multidisciplinaria (CLIMUZAC) de la unidad Académica de Odontología de la UAZ. Archivos Venezolanos de Farmacología y Terapéutica, 31(2), 23-31

Patrick R. Murray, Ken S. Rosenthal, Michael A. Pfaller. (2009). Microbiología Médica. Madrid, España: Elsevier. 
Paz G, Arana P, \& Caicdeo L. (2014) Microorganismos ingresados al quirófano en dispositivos electrónicos en un hospital de tercer nivel de Cali 2014 rev. salud mov. 2015; 7(2): 24-35

Shaebth, L. J. (2019). Contamination of Portable Phones with Pathogenic Bacteria, A Comparative Study between Staff at Al Hussain Teaching Hospital and Staff at Samawa Technical Institute. Indian Journal of Forensic Medicine \& Toxicology, 13(2).

Villacrés Yancha D \& Zurita Solís M. (2017). Grado de contaminación en los teléfonos celulares de docentes y estudiantes que realizan actividades en la clínica odontológica. Dominio de las Ciencias.3(1): 50-72. 